\title{
Editorial
}

\section{Fear of the novel coronavirus}

\author{
David J Kelvin ${ }^{1}$, Salvatore Rubino² \\ ${ }^{1}$ International Institute of Infection and Immunity, Shantou University Medical College, Shantou, Guangdong, \\ China; and Department of Microbiology and Immunology, Faculty of Medicine, Dalhousie University, Halifax, Nova \\ Scotia, Canada. Canadian Centre for Vaccinology, IWK Health Centre, Halifax, Nova Scotia, Canada. Senior editor, \\ JIDC \\ ${ }^{2}$ Dipartimento di Scienze Biomediche, Universita' degli Studi di Sassari, Sassari, Italy. Editor-in-Chief, JIDC
}

Key words: 2019-nCoV; outbreak; China.

J Infect Dev Ctries 2020; 14(1):1-2. doi:10.3855/jidc.12496

(Received and Accepted 30 January 2020)

Copyright (C) 2020 Kelvin et al. This is an open-access article distributed under the Creative Commons Attribution License, which permits unrestricted use, distribution, and reproduction in any medium, provided the original work is properly cited.

The Global health community is now facing the third coronavirus crisis in just less than twenty years. SARS-CoV emerged in 2002 [1], followed MERS in 2012 [2], and now nCoV (Wuhan) in late 2019.

The lessons from the days of SARS seem very relevant today. Just a few weeks ago, on 31 December 2019, the Wuhan Municipal Health Commission announced a cluster of cases, the report of a possible outbreak of a mysterious new pneumonia illness in the city of Wuhan, the capital of Hubei Province in the Peoples Republic of China (PRC). A novel coronavirus, designated 2019-nCoV, was found to be associated with patients in the outbreak. With remarkable speed, the virus was sequenced and released to the public by the China Novel Coronavirus Investigation and Research Team [3]. This was a remarkable achievement.

The novel coronavirus has a homology with SARS and tools for rapid diagnostic testing have been developed [4]. As of today, 28 January 2020, the known facts, according to the Chinese National Health Committee reported by ProMED-mail post, a program of the International Society for Infectious Diseases [5] are the following: $>5900$ confirmed cases of infection caused by the novel virus in 30 provinces, including over 1200 severe cases and 132 deaths. Furthermore, there are many more suspected cases. The relatively good news is that over 100 cases have been cured.

The last day of January WHO has declared the outbreak of novel coronavirus (2019-nCoV) a Public Health Emergency of International Concern [6].

Like SARS, there are now travel-related cases abroad in Hong Kong, Macau, Taiwan, Thailand, South
Korea, Japan, Malaysia, Viet Nam, Singapore, Sri Lanka, Nepal, Germany, France, the USA, Canada, Australia.

Flights out of Wuhan areas are cancelled and many countries are organizing special travel to bring back expatriates from quarantined areas.

The steady increase in case numbers, however, presents a challenge for epidemiologists as well as government officials. In the early stages of the outbreak, the epicenter appeared to be a wet market in Wuhan. The transmission chain to humans was thought to be zoonotic, a likely inference. The increasing case numbers and lack of contact with wet market animals for many patients, and contact investigations, make a strong case for human-to-human transmission.

The declaration of the Chinese National Health Committee and WHO, as well as the identification of third-generation human to human transmission, brings back vivid memories of SARS days. Wuhan, a city of 8-11 million inhabitants, is now shut down. Other cities in China are also now shut down, further recalling the situation in Sierra Leone when the city was under total quarantine due to an Ebola outbreak, which led to a civil crisis with violence and social anxiety.

In this complicated situation, the simple question is, are we prepared? Other more difficult questions include: Will the global community be able to win the war on $2019 \mathrm{nCoV}$ with public health measures? Will the Peoples Republic of China be able to halt the spread of $2019 \mathrm{nCoV}$ during the largest holiday of the year, the Chinese New Year/Spring Festival? Will the virus mutate to be more efficient in human-to-human 
transmission? Can we build vaccines and anti-virals in time for use in this battle?

We also wonder, when will we invest in the war on infectious disease? President Trump recently announced the formation of the US Space Force, but where is the trillion-dollar budget for the war against infectious disease? Where is the United States Infectious Disease Force? As a global community we need to invest in this war, so we can save millions of lives and be prepared for the next pandemic. Who has the courage to lead in this war?

In Geneva, Switzerland, on 23 January 2020, WHO released the statement of the meeting of the International Health Regulation (IHR) Emergency Committee [7] regarding the outbreak of novel coronavirus provided advice and information for the People's Republic of China, and to the global community. Are all countries ready to follow the advice?

The weakest part of the chain to stop the spread of the current and future epidemics may be developing countries. Especially in Africa, where there is insufficient infrastructure to identify the virus using real time PCR diagnostic tools and public health infrastructure for contact tracing and enforcing quarantine, the disease will spread rapidly. Are we ready to invest in these countries to prevent the deaths of millions of people?

What is clear is that all the eyes of world are looking to China. The situation there is being monitored every single minute by international agencies, newspapers, television, and social networks. However, we must not forget our Developing Country partners. They, too, will need vaccines, antivirals, public health resources, and healthcare workers to deal with a possible nCoV 2019 epidemic.

Preparedness and quick responses are necessary, but solidarity and cooperation are also key to fighting emerging infectious diseases all over the world.

The JIDC looks forward to helping in this epidemic (and maybe soon a pandemic) by publishing important information that provides the Global community with research updates on the 902-494-5125 $2019 \mathrm{nCoV}$.

\section{References}

1. Zhong NS, Zheng BJ, Li YM, Poon, Xie ZH, Chan KH, Li PH, Tan SY, Chang Q, Xie JP, Liu XQ, Xu J, Li DX, Yuen KY, Peiris, Guan Y (2003) Epidemiology and cause of severe acute respiratory syndrome (SARS) in Guangdong, People's Republic of China, in February, 2003. Lancet 362: 1353-1358.

2. Al-Ahdal MN, Al-Qahtani AA, Rubino S (2012) Coronavirus respiratory illness in Saudi Arabia. J Infect Dev Ctries 6: 692694. doi: $10.3855 /$ jidc. 3084

3. Zhu N, Zhang D, Wang W, Li X, Yang B, Song J, Zhao X, Huang B, Shi W, Lu R, Niu, P, Zhan F, Ma X, Wang D., Xu W, Wu G, Gao GF, Tan W, for the China Novel Coronavirus Investigating and Research Team (2020) A novel Coronavirus from patients with pneumonia in China, 2019. N Engl J Med. [Epub ahead of print]

4. World Health Organization (2020) Laboratory testing for 2019 novel coronavirus (2019-nCoV) in suspected human cases. Available: $\quad$ https://www.who.int/healthtopics/coronavirus/laboratory-diagnostics-for-novelcoronavirus. Accessed: 25 January 2020.

5. International Society for Infectious Diseases. ProMED-mail Available: http://www.promedmail.org. Accessed: 30 January 2020.

6. World Health Organization (2020) Statement on the second meeting of the International Health Regulations (2005) Emergency Committee regarding the outbreak of novel coronavirus (2019-nCoV). Available: https://www.who.int/news-room/detail/30-01-2020-statementon-the-second-meeting-of-the-international-healthregulations-(2005)-emergency-committee-regarding-theoutbreak-of-novel-coronavirus-(2019-ncov) Accessed: 1st February, 2020.

7. World Health Organization (2020) Statement on the meeting of the International Health Regulations (2005) Emergency Committee regarding the outbreak of novel coronavirus (2019nCoV). Available: https://www.who.int/news-room/detail/2301-2020-statement-on-the-meeting-of-the-internationalhealth-regulations-(2005)-emergency-committee-regardingthe-outbreak-of-novel-coronavirus-(2019-ncov). Accessed: 25 January 2020.

\section{Corresponding author}

David J Kelvin

Department of Microbiology and Immunology, Faculty of Medicine, Dalhousie University, Halifax, Nova Scotia, Canada Tel: 1-647-529-3556

Email: dkelvin@jidc.org

Conflict of interests: No conflict of interests is declared. 